\title{
Antigen induced arthritis in beige (Chediak-Higashi) mice
}

\author{
Joost Schalkwijk, Leo A B Joosten, Wim B van den Berg, Levinus B A van de Putte
}

\begin{abstract}
Mice with the beige mutation, which are known to be deficient for leucocyte elastase and cathepsin $\mathbf{G}$, were used to investigate the role of neutral proteases in a model for antigen induced arthritis. Surprisingly, it was shown that in this model of arthritis, using methylated bovine serum albumin as an antigen, C57/black/6 'beige' mice (deficient for leucocyte neutral proteases) developed a more severe form of arthritis than the control mice ('black' mice), resulting in a higher degree of tissue damage. The incidence and degree of bone apposition and destruction of articular cartilage at day 21 after induction of arthritis were significantly higher in the beige mice. These findings could not be ascribed to differences in the cellular immune response to methylated bovine serum albumin. Autoradiographic detection of radiolabelled methylated bovine serum albumin suggested that more antigen is retained in the joints of beige mice than in black mice, which might account for the sustained arthritis and the concomitant tissue damage. These findings do not support the contention that leucocyte elastase and cathepsin $\mathbf{G}$ contribute to the pathogenesis of joint destruction in this model.
\end{abstract}

Recently, a mutant mouse has been described which is deficient for polymorphonuclear leucocyte elastase and cathepsin G. ${ }^{1}$ This mutation, the so-called 'beige' gene, represents a putative model for the Chediak-Higashi syndrome in humans, with which it has several features in common, such as the giant lysosomes and the neutral protease deficiency. The beige mouse is therefore a suitable model for investigating the role of neutral proteases in various inflammatory conditions. We have recently described the effect of experimental arthritis, using the model of zymosan induced arthritis, in beige mice. ${ }^{2}$ It was found that although in vitro beige polymorphonuclear leucocytes caused less cartilage degradation, the tissue damage resulting from inflammation was not significantly different from that in the black mice. It was therefore concluded that polymorphonuclear leucocyte elastase and cathepsin $\mathrm{G}$ were not the main mediators of cartilage breakdown in this model. Because in a glomerulonephritis model based on immunological mechanisms we found significant differences between beige and black mice $^{3}$ we sought to compare the effect of an immunologically mediated experimental arthritis on beige and black mice. We therefore chose the model of allergic arthritis which uses methy- lated bovine serum albumin as an antigen, as described before. ${ }^{4}$ We have previously shown that part of the inflammatory reaction in this model, at least in the acute phase, is dependent on hydrogen peroxide generated by activated inflammatory cells. ${ }^{5}$ As in the zymosan induced arthritis model, the findings in this study do not support a role for neutral proteases.

\section{Materials and methods}

ANIMALS

Male, normal (black) C57Bl/6 and beige C57BV/6 $(\mathrm{bg} / \mathrm{bg})$ mice were obtained from Harlan Olac, UK. The animals (aged 10-16 weeks) were fed a standard diet and tap water freely.

\section{CHEMICALS}

Methylated bovine serum albumin was obtained from Sigma Chemicals Co, USA. Methoxysuccinyl-alanyl-alanyl-prolyl-valyl-aminomethylcoumarin (MAAPV-AMC) was obtained from Bachem, Bubendorf, Switzerland. ${ }^{125} \mathrm{I}$ was obtained from Amersham, Bucks, UK.

\section{ELASTASE ASSAY}

Elastase was used as a marker enzyme to compare beige and black polymorphonuclear leucocytes. This enzyme was assayed as previously described using the fluorogenic substrate MAAPV-AMC. ${ }^{6}$

\section{INDUCTION OF ARTHRITIS}

Joint inflammation was induced as described previously. ${ }^{4}$ Briefly, mice were immunised with methylated bovine serum albumin in complete Freund's adjuvant, and arthritis was induced by injection of $60 \mu \mathrm{g}$ of the antigen in the right knee joint three weeks after the primary immunisation. This type of inflammation is dependent on $T$ lymphocytes and is characterised by an infiltrate rich in polymorphonuclear leucocytes in the acute phase (first week) and a mononuclear infiltrate in the chronic phase (up to four weeks). The immune status of the animals (delayed type hypersensitivity against methylated bovine serum albumin) was measured by skin testing. Antigen $(10 \mu \mathrm{g})$ was injected in the right ear and the swelling after 24 and 48 hours was measured with a caliper. ${ }^{4}$

\section{MEASUREMENT OF ARTHRITIS}

Joint inflammation was measured at days 2, 5 , 7 , and 21 by the technetium-99m method. ${ }^{7}$ 
Briefly, the accumulation of ${ }^{99 \mathrm{~m}} \mathrm{Tc}$ is measured in the right $(R)$ and left $(L)$ control knee joint and expressed as a ratio $(R / L)$. This ratio is taken as a measure for joint swelling. Ratios above $1 \cdot 1$ were considered to indicate inflammation of the right knee joint.

\section{RETENTION OF RADIOLABELLED METHYLATED BOVINE SERUM ALBUMIN}

Methylated bovine serum albumin was radiolabelled by the chloramine $\mathrm{T}$ method. ${ }^{8}$ To investigate the effect of arthritis on the clearance of antigen from the inflamed joint in the beige and normal mice radiolabelled antigen $(37 \mathrm{kBq})$ was injected, and the retained antigen was monitored by external gammacounting or by autoradiography. Previous studies have indicated that this method does follow the fate of the injected antigen and that the measured radiolabel actually represents immunoreactive methylated bovine serum albumin. ${ }^{8}$

\section{HISTOLOGY AND AUTORADIOGRAPHY}

Mouse knee joints (six to eight in each group at each timepoint) were processed for histology and autoradiography. ${ }^{9}$ A histological examination was made on days 2, 5, and 21. Arthritis was scored on serial sections (haematoxylin and eosin staining). Infiltration, cartilage damage, and bone apposition were scored semiquantitatively. ${ }^{10}$ Antigen retention was visualised by autoradiography of ${ }^{125}$ I labelled methylated bovine serum albumin, and was scored on a four point scale. All histological examinations were performed 'blindly' by two observers.

\section{Results}

MEASUREMENT OF EXPERIMENTAL ARTHRITIS IN BEIGE AND BLACK MICE

Black and beige mice were immunised with methylated bovine serum albumin in complete Freund's adjuvant. No differences in delayed type hypersensitivity (skin testing) were found between the two strains (data not shown). Arthritis was induced by the intra-articular injection of $60 \mu \mathrm{g}$ of antigen in saline. Table 1 shows the time course of arthritis as assessed by ${ }^{99 m}$ Tc uptake, which is taken as a measure of joint oedema. At days 7 and $21^{99 \mathrm{~m}} \mathrm{Tc}$ uptake was significantly higher in the beige (neutral protease deficient) mice than in the black mice, indicating that vascular effects of inflammation were prominent in the beige mice. For all

Table 1: Time course of arthritis in beige and black mice. Values are means $(S D)$

\begin{tabular}{lll}
\hline Day & \multicolumn{2}{l}{ Ratio of ${ }^{99 m} T c$ uptake } \\
\cline { 2 - 3 } & Beige mice & Black mice \\
\hline 2 & $2 \cdot 16(0 \cdot 30)$ & $2 \cdot 37(0 \cdot 35)$ NS \\
5 & $1.84(0 \cdot 19)$ & $1 \cdot 58(0 \cdot 28)$ NS \\
7 & $1.80(0 \cdot 11)$ & $1 \cdot 38(0 \cdot 13)^{*}$ \\
21 & $1 \cdot 27(0 \cdot 10)$ & $1.03(0 \cdot 10)^{*}$ \\
\hline
\end{tabular}

Seven to eight mice a group were injected intra-articularly with $60 \mu \mathrm{g}$ of methylated bovine serum albumin in the right knee join at day 0 . Arthritis was measured at several intervals by the technetium uptake method (ratio of right and left knee joint). ${ }^{*} \mathrm{p}<0.001$, Wilcoxon rank sum test. experiments the elastase content of polymorphonuclear leucocytes from both strains was measured $^{2}$ as a routine check of the neutral proteinase deficiency. For the groups of mice used in these studies the elastase content of beige mice was always found to be less than $10 \%$ of that of the black mice (data not shown).

\section{HISTOLOGY OF ARTHRITIS}

Histological examination of the joints showed that the amount of cellular infiltrate in the beige mice was higher throughout the inflammatory response, though it only reached statistical significance at day 5 (table 2). Figure 1 shows that the infiltrate and exudate were predomi-

Table 2: Histological examination of arthritis in beige and black mice. Values are means (SD)

\begin{tabular}{lllll}
\hline Day & Mice & Infiltrate & $\begin{array}{l}\text { Cartilage } \\
\text { damage }\end{array}$ & $\begin{array}{l}\text { Bone } \\
\text { apposition }\end{array}$ \\
\hline 2 & $\begin{array}{l}\text { beige } \\
\text { black }\end{array}$ & $1.2(0.4)$ & ND & ND \\
& $1.3(0.5)$ & ND & ND \\
5 & $\begin{array}{l}\text { beige } \\
\text { black }\end{array}$ & $\begin{array}{l}3.0(0.1) \\
1.9(0.5)^{*}\end{array}$ & ND & ND \\
& $\begin{array}{lll}\text { beige } \\
\text { black }\end{array}$ & $1.4(0.5)$ & $2.6(0.8)$ & ND \\
& $1.1(0.7)$ & $1.3(1.0) \dagger$ & $1.0(1.0) \ddagger$
\end{tabular}

Seven to eight mice a group were injected with $60 \mu \mathrm{g}$ of methylated bovine serum albumin at day 0 . At several intervals animals were killed for histological examination. The amount of cellular infiltrate in the synovium and periosteum was scored semiquantitatively on serial sections at days 2,5 , and 21 . Cartilage damage and bone apposition was only present in the chronic phase of arthritis (day 21). The histological grading is given on a four point scale in proportion to severity.

${ }^{*} \mathrm{p}<0.005 ; \nmid \mathrm{p}<0.01 ; \neq \mathrm{p}<0.02$, Wilcoxon rank sum test.

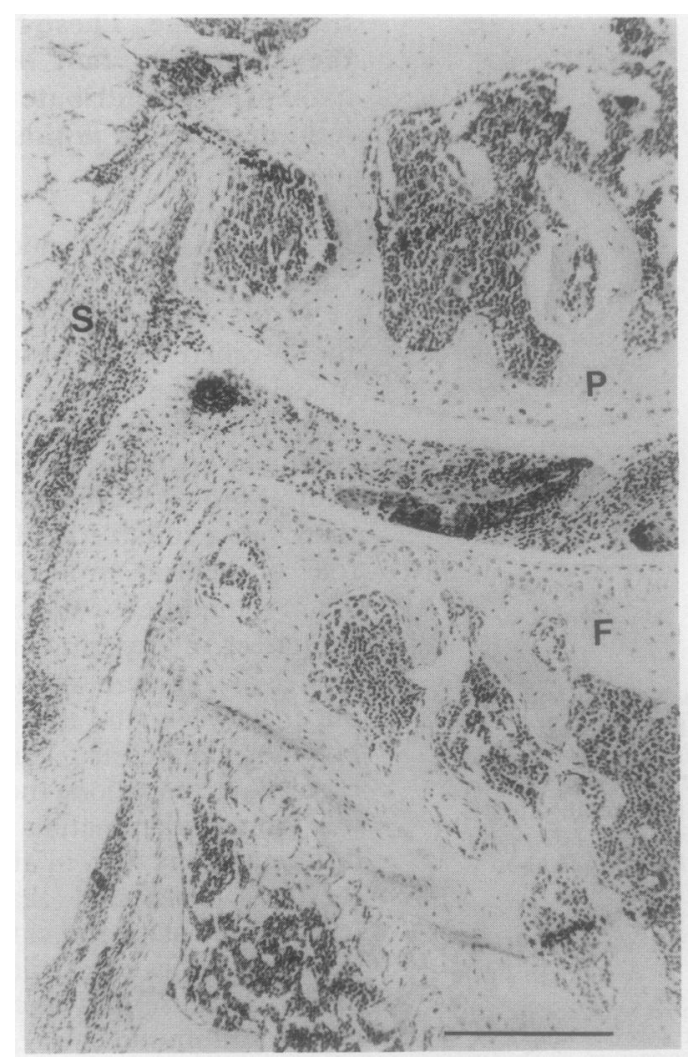

Figure 1: Arthritic knee joint of C57Bl/6 beige mice at day 2 after induction of inflammation. Note the exudate in the joint space and the cellular infiltration of the synovium (mainly polymorphonuclear leucocytes). $P=$ patella; $F=$ femur; $S=$ synovium. (Haematoxylin and eosin staining.) $B a r=100$ $\mu \mathrm{m}$. 
Figure 2: Foint of $a$ C57Bl/6 beige mouse at day 21 after induction of damage is visible in patella devoid of intact chondrocytes (arrows). $P$ = patella; $F=$ femur; (Haematoxylin and eosin staining.) Bar $=100 \mu \mathrm{m}$ arthritis. Extensive cartilage and femur. Large areas are

nantly composed of polymorphonuclear leucocytes in the acute phase. At day 21, when inflammation was waning, a significant difference in irreversible end stage joint destruction was seen between the two strains (table 2). The beige mice then showed considerably more cartilage destruction and apposition of newly formed bone than the black mice. Figures 2 and 3 show the extent of joint deformation resulting from this type of inflammation in the beige

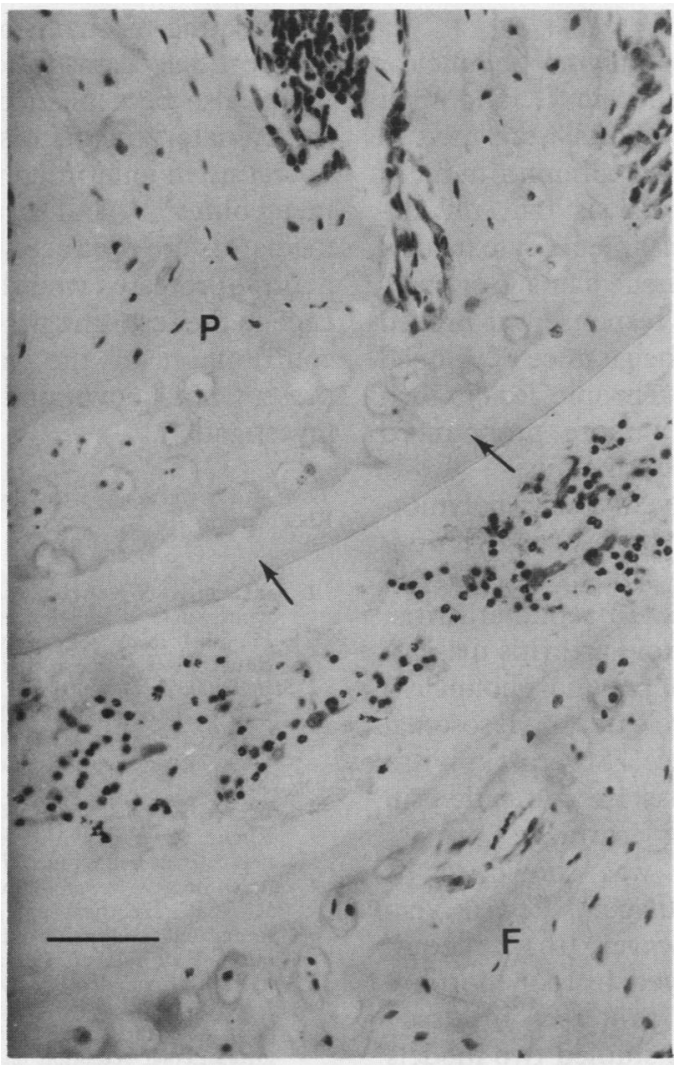

Figure 3: foint of a C57Bl/6 beige mouse at day 21 after induction of arthritis. Formation of new bone is prominent at the lateral sides of the femur. $F=$ femur; $N=$ new bone. (Haematoxylin and eosin staining.) Bar $=100 \mu \mathrm{m}$ Arrows = old bone margin mice: total destruction of articular cartilage and enormous humps of newly formed bone.

ANTIGEN RETENTION IN BEIGE AND BLACK MICE The data described above are contrary to what would be expected if neutral proteases had a role in joint destruction during inflammation. Surprisingly, cartilage destruction was even more severe in the beige mice. A possible explanation for this phenomenon might be that polymorphonuclear leucocyte neutral proteases actually assist with the elimination of the inflammatory stimulus-for example, by degradation of immune complexes, and thereby contribute to attenuation of the inflammatory response rather than promoting it. To investigate this possibility we measured the clearance of antigen from the inflamed joint by following the amount of radiolabelled antigen during the course of arthritis, using external gammacounting. ${ }^{5}$ It was found that the black mice eliminated the antigen factor faster than the beige mice, though the difference never reached significance (data not shown). As external gammacounting of radiolabelled antigen is a rather crude method for detecting the antigen (as it measures antigen in the entire knee joint, including some of the periarticular tissues) we also studied the fate of the injected antigen in situ, using autoradiography at day 8 after injection of radiolabelled antigen. Previous studies have shown that radiolabelled material detected by autoradiography can be equated with immunoreactive antigen. ${ }^{8}$ When the amount of

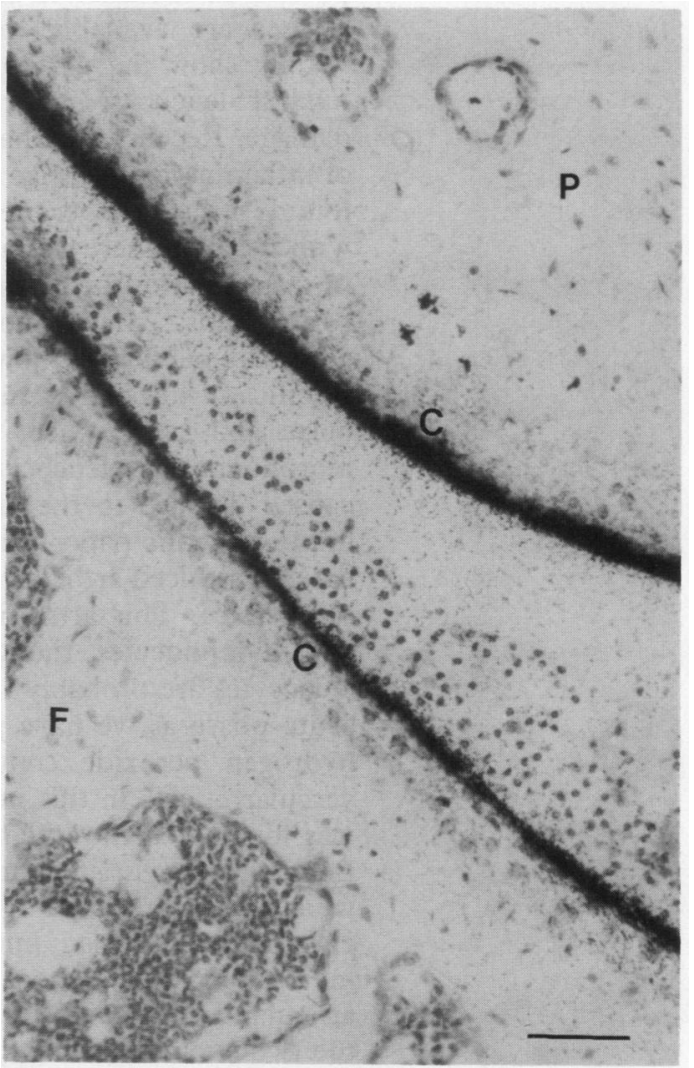

Figure 4: Autoradiograph of ${ }^{125}$ I labelled methylated bovine serum albumin retained in a knee joint at day 8 after injection of the antigen. Note that most of the silver grains are concentrated at the cartilage surfaces. $P=$ patella; $F=$ femur, $C=$ cartilage. (Haematoxylin and eosin staining.) $B a r=100$ $\mu \mathrm{m}$. 
retained antigen was assessed semiquantitatively with a four point scale on serial sections (as shown in fig 4) a small, but significant difference was found between beige and black mice. Black mice: mean (SD) $1.9(0.3)(n=9)$ and beige mice: $2 \cdot 6(0 \cdot 7)(n=6), p<0 \cdot 05$, Wilcoxon rank sum test. This indicates that at least at day 8 more antigen was present in the joints of beige mice than in those of black mice.

\section{Discussion}

Beige mice, deficient for polymorphonuclear leucocyte elastase and cathepsin $G$, and their normal C57/black/6 counterparts were used in the methylated bovine serum albumin induced arthritis model. The hypothesis that the deficiency of polymorphonuclear leucocyte neutral proteases would decrease tissue damage or chronicity of the inflammatory response was proved wrong. It was shown that beige mice developed a more serious and more chronic lesion than black mice, resulting in a more pronounced irreversible damage to articular tissues.

Neutral proteases derived from polymorphonuclear leucocytes have been strongly implicated in the degradation of articular cartilage in various arthritic conditions. In septic arthritis, gout, and in active rheumatoid arthritis massive infiltration and exudation of polymorphonuclear leucocytes lead to the release of lysosomal enzymes in the joint space. Several in vitro studies have shown that elastase and cathepsin $G$ can degrade articular cartilage proteoglycans, ${ }^{11} 12$ and elastase was shown to be present in rheumatoid cartilage. ${ }^{13} \mathrm{Few}$ in vivo studies are available, however, that unequivocally show the part played by polymorphonuclear leucocyte neutral proteases in tissue damage. Recently, we have studied two models of inflammation in beige and black mice. It was found that in experimental arthritis induced with zymosan there was no significant difference in inflammation or tissue damage between the two strains. ${ }^{2}$ In a model for experimental glomerulonephritis, however, we showed a significant difference in proteinuria between beige and black mice, suggesting that polymorphonuclear leucocyte neutral proteases caused damage to the glomerular basal membrane. ${ }^{3}$ In this paper we have investigated the antigen induced arthritis model using beige and black mice. This arthritis model is dependent on T lymphocytes, though polymorphonuclear leucocytes are probably the effector cells in the acute phase as we have previously shown that hydrogen peroxide contributes to the acute vascular effects in this model. ${ }^{5}$ Surprisingly, it was found that the inflammatory response and the amount of tissue damage in the beige mice were even higher than in the black mice. In the chronic phase beige mice show considerably more bone apposition and destruction of articular cartilage. The main difference between the two strains (as known so far) is the amount of elastase and cathepsin G. No differences in collagenase or acid protease content could be shown. ${ }^{1}$ We have also shown that there are no significant differences in the production of superoxide. $^{2}$ As the neutral proteases might, alternatively, assist in the removal of the inflammatory stimulus (proteolysis of antigen or immune complexes) we studied the clearance rate of labelled antigen from the joint. Our studies suggest a slight difference in antigen clearance between the two strains. The possible role of elastase and cathepsin $\mathrm{G}$ in the degradation of antigenic material is currently being investigated. In this model neutral proteases might eventually represent an off-switch mechanism for inflammation rather than a potentiating mechanism.

The tissue damage found in the beige mice might also be explained by the action of other inflammatory mediators that are thought to be operating in joint inflammation, such as oxygen metabolites ${ }^{5} 14$ and cytokines. ${ }^{15}$ When these mediators are produced in excess the absence of neutral proteases would not make much difference to the resulting tissue damage. The relative contribution of the various mediators is at present not known and is a subject of further investigation.

This work was supported by the Dutch League Against Rheumatism.

1 Takeuchi $K$, Wood $H$, Swank R T. Lysosomal elastase and cathepsin $G$ in beige mice. Neutrophils of beige (Chediakcathepsin $G$ in beige mice. Neutrophils of beige (Chediakcathepsin G. F Exp Med 1986; 163: 665-77.

2 Schalkwijk J, Joosten L A B, van den Berg W B, van de Putte L B A. Experimental arthritis in C57black/6 normal and beige (Chediak-Higashi) mice: in vivo and in vitro observations on cartilage degradation. Ann Rheum Dis 1988; 47: 940-6.

3 Schrijver G, Schalkwijk J, Robben J C M, Assmann K J M, Koene R A P. Antiglomerular basement membrane nephritis in beige mice. F Exp Med 1989; 169: 1435-48.

4 van den Berg W B, van de Putte L B A, Zwarts W A, Joosten L A B. Electrical charge of the antigen determines intraarticular antigen handling and chronicity of arthritis in mice. I Clin Invest 1984; 74: 1850-9.

5 Schalkwijk J, van den Berg W B, van de Putte L B A, Joosten L A B, van den Bersselaar L. Cationization of catalase, peroxidase and superoxide dismutase. Effect of improved peroxidase and superoxide dismutase. Effect of improved intraarticular retention on experim

6 Lammers A M, van de Kerkhof P C M, Schalkwijk J, Mier $P$ D. Elastase, a marker for neutrophils in skin infiltrates. Br $\mathcal{f}$ Dermatol 1986; 115: 181-6.

7 Kruijsen M W M, van den Berg W B, van de Putte L B A, van den Broek W J M. Detection and quantification of experimental joint inflammation in mice by measurement of ${ }_{640-2}$ Tc-pertechnetate uptake. Agents Actions 1981; 11:

8 van den Berg W B, van Beusekom H J, van de Putte L B A, $Z$ warts $W A$, van der Sluis $M$. Antigen handling in antigeninduced arthritis in mice: an autoradiographic and induced arthritis in mice: an autoradiographic and immunofluorescence study

9 van den Berg W B, Kruijsen MW M, van de Putte L B A, van Beusekom $H J$, van der Sluis $M, Z$ warts W A. Antigeninduced arthritis in mice: studies on in vivo cartilage proteoglycan synthesis and chondrocyte death. $\operatorname{Br} \mathcal{F} \operatorname{Exp}$ Pathol 1981; 62: 308-15.

10 Schalkwijk J, van den Berg W B, van de Putte L B A, Joosten $L A$, van der Sluis $M$. Effects of experimental joint inflammation on bone marrow and periarticular bone. A study of two types of arthritis using variable degrees of inflammation. Br 7 Exp Pathol 1985; 66: 435-44.

11 Janoff A. Feinstein G, Malemud C J, Elias J M. Degradation of cartilage proteoglycan by human leukocyte granule of cartilage proteoglycan by hum injury. 7 Clin Invest neutral proteases.

12 Schalkwiik J, van den Berg, van de Putte L B A, Joosten L A B. Elastase secreted by activated polymorphonuclear leucocytes causes damage and matrix degradation in intact leucocytes causes damage and matrix degradation in intact articular cartilage: escape from inactivation by alpha-1

13 Velvart M, Baici A, Sommermeyer G, et al. Degradation in vivo of articular cartilage in rheumatoid arthritis by vivo of articular cartilage in rheumatoid arthritis by leucocyte elastase from polymo

14 Blake D R, Hall N D, Bacon P A, Dieppe P A, Halliwell B, Gutteridge J M C. Effect of a specific chelating agent on animal models of inflammation. Ann Rheum Dis 1983; 42: 89-93.

15 Pettipher E R, Higgs G A, Henderson B. Interleukin-1 induces leucocyte infiltration and cartilage proteoglycan degradation in the synovial joint. Proc Natl Acad Sci USA 1986; 83: 8749-53. 